\title{
OPM3 ${ }^{\circledR}$ Portugal Project - Information Systems and Technologies Organizations - Outcome Analysis
}

\author{
David Silva $^{1}$, Anabela Tereso ${ }^{1}$, Gabriela Fernandes ${ }^{1}$, Isabel Loureiro ${ }^{1}$ and \\ José Ângelo Pinto², \\ ${ }^{1}$ Department of Production and Systems Engineering, \\ Algoritmi Centre, University of Minho, 4800-058 Guimarães, Portugal \\ ${ }^{2}$ Ambithus, 1600-546 Lisboa, Portugal \\ davidrenatosilva@gmail.com, \{anabelat, g.fernandes, ifloureiro\}@dps.uminho.pt, \\ jose.pinto@ambithus.com
}

\begin{abstract}
Increasing the maturity in Project Management (PM) has become a goal for many organizations, leading them to adopt maturity models to assess the current state of its PM practices and compare them with the best practices in the industry where the organization is inserted. One of the main PM maturity models is the Organizational Project Management Maturity Model (OPM3 ${ }^{\circledR}$ ), developed by the Project Management Institute. This paper presents the Information Systems and Technologies organizations outcome analysis, of the assesses made by the OPM3 ${ }^{\circledR}$ Portugal Project, identifying the PM processes that are "best" implemented in this particular industry and those in which it is urgent to improve. Additionally, a comparison between the different organizations' size analyzed is presented.
\end{abstract}

Keywords: Project Management; OPM3 ${ }^{\circledR}$; Maturity Models; Best Practices; Processes.

\section{Introduction}

Over the years, all kinds of organizations have attempted to define with precision their goals and objectives for short and long term and at the same time project strategies to achieve them. However, very often the strategies outlined do not allow to reach the results for which they were designed [1]. In order to address this problem, Project Management (PM) emerged as a powerful management solution, which is increasingly popular in several industries [2], as the Information Systems and Technologies (IST) industry.

The concept of maturity, when applied to organizations, might refer to a state where organizations are in a perfect condition to achieve their objectives. Project maturity would then mean that organizations are perfectly conditioned to deal with their projects [3]. To improve their PM maturity, organizations need to obtain a total control and measurability of their PM processes, using maturity models to test and compare their current performance against Best Practices (BP) [4, 5]. One of these models is the Organizational Project Management Maturity Model $\left(\mathrm{OPM}^{\circledR}{ }^{\circledR}\right.$ ), proposed by the Project Management Institute (PMI), that joins together not only the standards for managing projects, programs and portfolios, but also the necessary organizational conditions that enable organizational PM to function efficiently and effectively [6]. 
The main goal of this paper is to perform an analysis of the state of IST Portuguese organizations maturity in the adoption of project management practices, and present PM and Portfolio Management processes, and Organizational Enablers (OE) areas that are "best" implemented by these organizations, identifying for each process and area if there are statistically significant differences between different organizations' size. First the main characteristics of the OPM $3^{\circledR}$ model are explained. Next the OPM3 ${ }^{\circledR}$ Portugal Project and the research methodology used are presented. Then the results obtained for the IST organizations are exhibited and discussed. Finally, the main findings that emerged from this study are presented, as well as suggestions for future research.

\section{$2 \quad$ OPM3 ${ }^{\circledR}$ Model}

OPM3 ${ }^{\circledR}$ is a model that helps organizations to develop capabilities that underpin the management processes of all their projects, connecting them with the corporate strategy. PMI released the first edition of OPM3 ${ }^{\circledR}$ in 2003 [7]. In 2008, the model has been updated with the publication of the second edition [8] and in 2013 the third and latest edition was published [9].

One of the main characteristics of $\mathrm{OPM} 3^{\circledR}$ is the assessment of PM maturity, through the existence of a standardized set of BP [10]. According to PMI [9 p.238], $\mathrm{BP}$ "refer to the methods, currently recognized within a given industry or discipline, to achieve a stated goal or objective". In OPM $3^{\circledR}$ context, each BP is dependent on a set of Capabilities (specific competency that must exist in an organization to perform PM processes and deliver PM products and services) that need to be developed for a BP to be recognized as implemented [9, 10]. The existence of a Capability is demonstrated by the existence of one or more Outcomes, which are tangible or intangible results of performing a Capability $[9,10]$.

One of the main differences of the OPM $3^{\circledR}$ compared to other maturity models is the fact that it is a multidimensional model, being possible to determine the maturity of an organization under different perspectives [11]. One of these perspectives is the exhibition of BP and respective Capabilities through the progression in four stages of processes maturity: Standardize, Measure, Control and continuously Improve (SMCI). Another perspective is associated with the progression of the BP and respective Capabilities within three domains: PM, Program Management (set of projects with common goal) and Portfolio Management (group of projects and/or programs and operational activities which share common resources). In addition to these two dimensions, OPM3 ${ }^{\circledR}$ incorporates the five PM process groups (Initiating, Planning, Executing, Monitoring and Controlling, and Closing), designated by the PMBoK Guide $^{\circledR}$, and identifies the Capabilities and the BP regarding its association with these five processes $[9,11,12]$.

There is also another BP category in OPM ${ }^{\circledR}$, the OE. The OE are "practices that can be leveraged to support the implementation of Best Practices in portfolios, programs, and projects in support of strategic goals" [9 p.240]. The presence of an $\mathrm{OE}$ indicates that an organization has matured to the point of establishing a stable organizational PM practice environment and has adopted the disciplines of project, program and portfolio management, to achieve this [9]. 
In summary, OPM3 ${ }^{\circledR}$ was created for organizations of any size, geographical location or sector of activity, which aim to identify the maturity in the management of their projects, programs, portfolios, and the practices established by their project managers, possessing a set of BP as a basis of comparison, recognized and accepted throughout the world [11].

\section{$3 \quad$ OPM3 $^{\circledR}$ Portugal Project and Research Methodology}

Ambithus, a Portuguese organization of PM consulting, training, research and development, settled the OPM3 ${ }^{\circledR}$ Portugal Project. This project seeks to perform a comprehensive analysis of the state of Portuguese industry with regard to the degree of maturity in the adoption of project, program, and portfolio management methodology. The project was chartered because of the need felt by the organization and other project initiators and mentors to improve the way Portuguese industries initiate, choose, manage, control and close their projects. The understanding of this need was very helpful to taking the proper actions and taking advantage of an established funding system for research incentives for these kinds of projects, supported by the European Union Government but managed by the state authorities. The main objective of the project is to evaluate 100 organizations, from various sectors of activity, and perform an analysis of organizational PM maturity, presenting an improvement plan for each sector of activity.

The project started in 2011, was financed by European Union research founding, which means that the individual results for each participating organization - the assessment of PM maturity and the Improvement Plan - did not represent a cost for the participating organizations [13].

OPM $3{ }^{\circledR}$ Portugal Project is based on the second edition of the OPM3 ${ }^{\circledR}$ model, which is aligned with the fourth edition of PMBoK Guide ${ }^{\circledR}$ and with the second edition of The Standard of Program Management and The Standard for Portfolio Management, because at the OPM3 ${ }^{\circledR}$ Portugal Project starting date, these were the latest versions of the standards.

This project is following an approach divided into four steps: Planning and Organizing, Company Assessment, Sectorial Assessment and Country Level Assessment. In the first step, all generic procedures, management structures and control processes were defined for the project, as well as more detailed planning activities and processes [14]. In addition, it was created a management information system, designed by Ambithus researchers with the contribution of the academic partners, for the organizations' assessment work and data analysis. This information system is complementary with PMI's OPM3 ${ }^{\circledR}$ ProductSuite (the information system certified by PMI) and overcomes some of its limitations, such as, it can be only used by $\mathrm{OPM} 3{ }^{\circledR}$ certified consultants, or only allowing the introduction of the overall result of the organization for each OPM ${ }^{\circledR}$ question, instead of the response of each person interviewed [14].

The second step begins with the signing of a cooperation protocol, between the organization that will be assessed and Ambithus. The initial process of intervention includes meetings and a series of interviews with different people from different roles within the organization. Being concluded this phase, data gathering was accomplished 
to assess the current maturity of organizations in PM. Two documents are produced: the Assessment Report and the Improvement Plan. In the first one, the organization maturity results in PM are expressed in several ways, such as the overall maturity or the relative maturity by BP category (Project, Program, and Portfolio Management and $\mathrm{OE}$ ) and SMCI stages. The Improvement Plan intends to give the organizations an indication of the path to increase their maturity.

The third step is related to the Sectorial Assessment. The results of the various assessments performed in the organizations are summarized to create measures of sectorial capacity in PM. After the analysis and validation of the obtained results, an Improvement Plan for the industry sector will be presented and discussed [14].

In the final step, the results of the sectorial assessments will be compared, to identify areas of strengths and weaknesses, and the final result in each sector will be used to create general indicators on the Portugal's country capacity in PM [14].

In summary, this project will create several benefits for the Portuguese organizations, such as identify the BP that can support the organizational strategy for the implementation of projects with success and identify specific Capabilities that can give rise to BP for the organization [14].

Currently OPM3 ${ }^{\circledR}$ Portugal Project is in the second step, Company Assessment. This paper analyses the interim results of this project. In July 2014, thirty three organizations have already fully concluded their assessment in OPM3 ${ }^{\circledR}$ Portugal Project, which means that a presentation and validation of their Improvement Plans were already presented to each organization assessed [15]. From these thirty three organizations, eighteen are from IST, and this paper focus on the results obtained from these eighteen IST organizations.

In step two of the OPM3 ${ }^{\circledR}$ Portugal Project execution, the OPM3 ${ }^{\circledR}$ consultants collected information about the organizations namely, the Industry Type, the Annual Turnover and the Number of Employees. In order to classify the eighteen organizations according to their organizational size, European Commission criteria were used [16]. The organizations can be classified as Micro, Small, Medium and Large. This classification takes into account the framework of each organization within the limits of the following criteria:

- Number of permanent Employees of the organization.

- Annual Turnover or Annual Balance Sheet Total.

Table 1 shows the limits for the organizations size classification.

Table 1. European Commission recommendations for the size of organizations.

\begin{tabular}{|c|c|c|c|c|}
\hline $\begin{array}{c}\text { Organization } \\
\text { Category }\end{array}$ & $\begin{array}{c}\text { Number of } \\
\text { Organizations } \\
\text { Assessed }\end{array}$ & $\begin{array}{c}\text { Number of } \\
\text { Employees }\end{array}$ & Annual Turnover & $\begin{array}{c}\text { Annual Balance } \\
\text { Sheet Total }\end{array}$ \\
\hline Large & 4 & $\geq 250$ & $>€ 50$ million & or $>€ 43$ million \\
\hline Medium & 8 & $<250$ & $\leq € 50$ million & or $\leq € 43$ million \\
\hline Small & 6 & $<50$ & $\leq € 10$ million & or $\leq € 10$ million \\
\hline Micro & 0 & $<10$ & $\leq € 2$ million & or $\leq € 2$ million \\
\hline
\end{tabular}

In the OPM3 ${ }^{\circledR}$ Portugal Project assessments, the organization's annual balance sheet was not collected. This lack of information was not a limitation to classify the organizations, since the analysis of the number of employees and the annual turnover was consensual to categorize the eighteen organizations. 
A descriptive analysis was performed with the Statistical Product and Service Solutions (SPSS) [17] in order to categorize the organizations according to their size. Afterwards, an identification of the PM and Portfolio Management processes, and OE areas that are "best" implemented and those that are urgent to improve, regarding organizations' size, was made. Finally, to test whether there was a relation between the organization size and the use of the identified processes, a non-parametric analysis was conducted.

\section{Results Analysis}

Tables 2, 3 and 4 present, for the IST organizations assessed in the OPM3 ${ }^{\circledR}$ Portugal Project, the average percentage and ranking of PM and Portfolio Management processes and OE areas, organized by size. The Program Management processes were excluded from the data analysis as the organizations under study did not present processes for programs different than those they have for projects. Results of the top five processes or areas per organization size are highlighted in bold and grey in the three tables.

Table 2 shows that on average, Process Ownership is the process with the higher percentage of implementation. Notice that it appears in first position in the Large and Small size organizations and in second position in Medium size. The processes Monitor and Control Project Work, Conduct Procurements, Collect Requirements and Define Activities, are also present in the overall top five. In addition, the other processes that appear in the top five should also be stressed: Perform Integrated Change Control and Report Performance in Large organizations, Distribute Information and Control Schedule in Medium organizations and Develop Project Management Plan and Define Scope in Small organizations.

The five PM processes with lower average percentage of implementation are related to Risk Management. Furthermore, it should be noted that for Small IST organizations, the five processes with a lower average of implementation present the value zero, which means that these processes are not simply implemented in any Small organization!

Comparing the three different organizations size, clearly Large organizations were those who obtained better results in PM processes, with averages above $87 \%$ in the five processes with higher average of implementation, and above $7 \%$ in the five processes with lower average of implementation. On the contrary, Small organizations obtained the lowest results for PM processes, with only three processes with averages above $50 \%$ and with six processes with average of $0 \%$.

Table 3 shows the results for Portfolio Management per organization size. Process Ownership, as in PM processes, is the process that most stands out because it occupies the first position for all types of organization sizes. It should also be stressed that the processes involving the components of portfolios (projects and programs) namely Authorize Components, Identify Components, Categorize Components, Prioritize Components, Evaluate Components and Select Components, in one way or another are presented in the top five of the three organization sizes, although their overall averages are low (below 18\%). 
Again, the lower results of the portfolio processes are related to Risk Management, which is consistent with the results observed in projects, and all organization sizes have their five processes with average of implementation equal or very close to zero.

Table 2. Average percentage and ranking of PM processes.

\begin{tabular}{|c|c|c|c|c|c|c|c|c|}
\hline \multirow{2}{*}{ Project Management Processes } & \multicolumn{2}{|l|}{ All } & \multicolumn{2}{|l|}{ Large } & \multicolumn{2}{|l|}{ Medium } & \multicolumn{2}{|l|}{ Small } \\
\hline & Average $(\%)$ & R. & Average (\%) & R. & Average (\%) & R. & Average (\%) & R. \\
\hline Process Ownership & 82.50 & 1 & 98.75 & 1 & 73.75 & 2 & 83.33 & 1 \\
\hline Develop Project Charter & 44.78 & 15 & 69.50 & 17 & 33.50 & 25 & 43.33 & 7 \\
\hline Identify Stakeholders & 23.95 & 31 & 37.50 & 30 & 22.63 & 34 & 16.67 & 22 \\
\hline Develop Project Management Plan & 46.61 & 13 & 47.75 & 27 & 44.25 & 19 & 49.00 & 4 \\
\hline Collect Requirements & 57.56 & 4 & 88.75 & 3 & 48.75 & 14 & 48.50 & 6 \\
\hline Define Scope & 56.33 & 7 & 73.75 & 11 & 50.63 & 12 & 52.33 & 3 \\
\hline Create Work Breakdown Structure & 32.83 & 26 & 63.75 & 21 & 42.00 & 21 & 0.00 & 38 \\
\hline Define Activities & 57.06 & 5 & 66.50 & 19 & 79.13 & 1 & 21.33 & 17 \\
\hline Sequence Activities & 45.66 & 14 & 65.50 & 20 & 45.62 & 17 & 32.50 & 13 \\
\hline Estimate Activity Resources & 52.17 & 10 & 72.50 & 14 & 59.13 & 6 & 29.33 & 14 \\
\hline Estimate Activity Durations & 49.11 & 11 & 73.25 & 12 & 58.63 & 7 & 20.33 & 19 \\
\hline Develop Schedule & 44.33 & 17 & 70.25 & 15 & 53.13 & 11 & 15.33 & 23 \\
\hline Estimate Costs & 43.00 & 18 & 54.25 & 24 & 43.75 & 20 & 34.50 & 12 \\
\hline Determine Budget & 31.50 & 27 & 56.75 & 23 & 31.50 & 27 & 14.67 & 26 \\
\hline Plan Quality & 18.44 & 37 & 40.50 & 29 & 21.25 & 37 & 0.00 & 39 \\
\hline Develop Human Resource Plan & 25.17 & 30 & 7.25 & 43 & 37.50 & 23 & 20.67 & 18 \\
\hline Plan Communications & 26.94 & 28 & 35.75 & 31 & 31.37 & 28 & 15.17 & 24 \\
\hline Plan Risk Management & 14.56 & 39 & 28.00 & 34 & 14.88 & 39 & 5.17 & 33 \\
\hline Identify Risks & 18.89 & 36 & 30.50 & 33 & 22.50 & 35 & 6.33 & 31 \\
\hline Perform Qualitative Risk Analysis & 9.95 & 40 & 28.00 & 35 & 8.38 & 41 & 0.00 & 40 \\
\hline Perform Quantitative Risk Analysis & 9.11 & 41 & 25.00 & 36 & 8.00 & 43 & 0.00 & 41 \\
\hline Plan Risk Responses & 8.44 & 43 & 10.50 & 42 & 13.75 & 40 & 0.00 & 42 \\
\hline Plan Procurements & 40.61 & 20 & 72.75 & 13 & 35.75 & 24 & 25.67 & 15 \\
\hline Direct and Manage Project Execution & 40.45 & 21 & 82.25 & 6 & 30.63 & 29 & 25.67 & 16 \\
\hline Perform Quality Assurance & 19.11 & 35 & 32.75 & 32 & 22.75 & 33 & 5.17 & 34 \\
\hline Acquire Project Team & 33.17 & 25 & 22.50 & 39 & 50.50 & 13 & 17.17 & 21 \\
\hline Develop Project Team & 16.67 & 38 & 19.75 & 41 & 20.50 & 38 & 9.50 & 29 \\
\hline Manage Project Team & 21.33 & 32 & 22.00 & 40 & 25.75 & 31 & 15.00 & 25 \\
\hline Distribute Information & 56.72 & 6 & 68.00 & 18 & 61.50 & 5 & 42.83 & 8 \\
\hline Manage Stakeholder Expectations & 19.61 & 34 & 24.25 & 37 & 27.25 & 30 & 6.33 & 32 \\
\hline Conduct Procurements & 58.22 & 3 & 78.50 & 7 & 55.25 & 8 & 48.67 & 5 \\
\hline Monitor and Control Project Work & 68.95 & 2 & 91.25 & 2 & 63.38 & 4 & 61.50 & 2 \\
\hline Perform Integrated Change Control & 47.50 & 12 & 88.75 & 4 & 47.38 & 16 & 20.17 & 20 \\
\hline Verify Scope & 33.89 & 24 & 59.50 & 22 & 39.00 & 22 & 10.00 & 28 \\
\hline Control Scope & 26.56 & 29 & 50.75 & 26 & 32.88 & 26 & 2.00 & 37 \\
\hline Control Schedule & 44.61 & 16 & 52.50 & 25 & 69.13 & 3 & 6.67 & 30 \\
\hline Control Costs & 42.50 & 19 & 77.50 & 8 & 48.00 & 15 & 11.83 & 27 \\
\hline Perform Quality Control & 21.17 & 33 & 44.00 & 28 & 23.25 & 32 & 3.17 & 35 \\
\hline Report Performance & 40.06 & 22 & 87.50 & 5 & 44.63 & 18 & 2.33 & 36 \\
\hline Monitor and Control Risks & 9.11 & 42 & 24.25 & 38 & 8.38 & 42 & 0.00 & 43 \\
\hline Administer Procurements & 55.11 & 8 & 76.75 & 10 & 54.13 & 9 & 42.00 & 9 \\
\hline Close Project or Phase & 38.39 & 23 & 70.25 & 16 & 22.13 & 36 & 38.83 & 10 \\
\hline Close Procurements & 52.89 & 9 & 77.50 & 9 & 54.13 & 10 & 34.83 & 11 \\
\hline Number of organizations assessed $=$ & 18 & & 4 & & 8 & & 6 & \\
\hline
\end{tabular}

Comparing the organizations size, once again, Large organizations are the ones that appear to have greater maturity in Portfolio Management, because they present a set of processes with averages of implementation relatively high (if compared with Medium and Small organizations) and very close to each other. 
Table 4 shows the seventeen $\mathrm{OE}$ areas that best facilitate the implementation of PM practices. It is possible to observe that Sponsorship received the best global ranking and the first position in the top five for Medium and Small organizations. Strategic Alignment, Organizational Project Management Policy \& Vision, Project Management Training and Organizational Project Management Practices are also present in the overall top five. Organizational Project Management Communities, Benchmarking and Project Management Metrics obtained the lower results.

Table 3. Average percentage and ranking of Portfolio Management processes.

\begin{tabular}{|l|c|c|c|c|c|c|c|c|}
\hline \multirow{2}{*}{ Portfolio Management Processes } & \multicolumn{2}{|c|}{ All } & \multicolumn{2}{c|}{ Large } & \multicolumn{3}{c|}{ Medium } & \multicolumn{2}{c|}{ Small } \\
\cline { 2 - 10 } & Average (\%) & R. & Average (\%) & R. & Average (\%) & R. & Average (\%) & R. \\
\hline Process Ownership & 53.50 & $\mathbf{1}$ & 60.50 & $\mathbf{1}$ & 36.83 & $\mathbf{1}$ & 75.00 & $\mathbf{1}$ \\
\hline Identify Components & 10.75 & $\mathbf{5}$ & 51.50 & $\mathbf{3}$ & 2.83 & 8 & 2.25 & $\mathbf{4}$ \\
\hline Categorize Components & 9.92 & 6 & 49.00 & $\mathbf{4}$ & 3.50 & 7 & 0.00 & 8 \\
\hline Evaluate Components & 6.17 & 7 & 12.00 & 8 & 8.00 & $\mathbf{5}$ & 0.50 & 6 \\
\hline Select Components & 2.42 & 10 & 8.50 & 10 & 2.00 & 9 & 0.00 & 9 \\
\hline Prioritize Components & 15.08 & $\mathbf{4}$ & 41.50 & 6 & 16.33 & $\mathbf{4}$ & 0.00 & 10 \\
\hline Balance Portfolio & 4.33 & 8 & 6.00 & 11 & 4.33 & 6 & 3.50 & $\mathbf{2}$ \\
\hline Communicate Portfolio Adjustment & 2.42 & 11 & 12.00 & 9 & 0.00 & 11 & 1.25 & $\mathbf{5}$ \\
\hline Authorize Components & 18.00 & $\mathbf{2}$ & 53.50 & $\mathbf{2}$ & 17.83 & $\mathbf{2}$ & 0.50 & 7 \\
\hline Identify Portfolio Risks & 0.17 & 12 & 1.00 & 12 & 0.00 & 12 & 0.00 & 11 \\
\hline Analyse Portfolio Risks & 0.17 & 13 & 1.00 & 13 & 0.00 & 13 & 0.00 & 12 \\
\hline Develop Portfolio Risk Responses & 0.00 & 15 & 0.00 & 15 & 0.00 & 14 & 0.00 & 13 \\
\hline Review and Report Portfolio Performance & 16.50 & $\mathbf{3}$ & 49.00 & $\mathbf{5}$ & 16.67 & $\mathbf{3}$ & 0.00 & 14 \\
\hline Monitor Business Strategy Changes & 4.17 & 9 & 15.50 & 7 & 1.17 & 10 & 3.00 & $\mathbf{3}$ \\
\hline Monitor and Control Portfolio Risks & 0.17 & 14 & 1.00 & 14 & 0.00 & 15 & 0.00 & 15 \\
\hline \multicolumn{1}{|c|}{ Number of organizations assessed } & 12 & & 2 & & 6 & & 4 \\
\hline
\end{tabular}

Globally the Large IST organizations obtained the "best" results in OE areas, which was expected because it was the organization size with "best" results in PM and Portfolio Management processes.

Table 4. Average percentage and ranking of OE areas.

\begin{tabular}{|l|c|c|c|c|c|c|c|c|}
\hline \multirow{2}{*}{ Organizational Enablers Areas } & \multicolumn{2}{|c|}{ All } & \multicolumn{2}{c|}{ Large } & \multicolumn{2}{c|}{ Medium } & \multicolumn{2}{c|}{ Small } \\
\cline { 2 - 9 } & Average (\%) & R. & Average (\%) & R. & Average (\%) & R. & Average (\%) & R. \\
\hline Organizational Project Management Policy \& Vision & 54.28 & $\mathbf{3}$ & 68.50 & $\mathbf{4}$ & 57.13 & $\mathbf{4}$ & 41.00 & $\mathbf{5}$ \\
\hline Strategic Alignment & 61.00 & $\mathbf{2}$ & 82.25 & $\mathbf{1}$ & 64.63 & $\mathbf{3}$ & 42.00 & $\mathbf{3}$ \\
\hline Resource Allocation & 51.22 & 6 & 56.75 & 13 & 55.50 & 6 & 41.83 & $\mathbf{4}$ \\
\hline Management Systems & 46.83 & 9 & 67.25 & 6 & 44.25 & 12 & 36.67 & 7 \\
\hline Sponsorship & 67.89 & $\mathbf{1}$ & 67.50 & $\mathbf{5}$ & 68.38 & $\mathbf{1}$ & 67.50 & $\mathbf{1}$ \\
\hline Organizational Structures & 47.94 & 7 & 71.25 & $\mathbf{3}$ & 55.00 & 7 & 23.00 & 10 \\
\hline Competency Management & 41.83 & 10 & 62.75 & 8 & 40.25 & 13 & 30.00 & 8 \\
\hline Individual Performance Appraisals & 39.33 & 13 & 48.00 & 15 & 48.88 & 8 & 20.83 & 11 \\
\hline Project Management Training & 53.39 & $\mathbf{4}$ & 76.75 & $\mathbf{2}$ & 67.13 & $\mathbf{2}$ & 19.50 & 12 \\
\hline Organizational Project Management Communities & 25.50 & 17 & 40.50 & 17 & 34.63 & 14 & 3.33 & 17 \\
\hline Organizational Project Management Practices & 51.83 & $\mathbf{5}$ & 61.50 & 9 & 56.87 & $\mathbf{5}$ & 38.67 & 6 \\
\hline Organizational Project Management Methodology & 39.95 & 11 & 66.75 & 7 & 44.88 & 11 & 15.50 & 15 \\
\hline Organizational Project Management Techniques & 47.67 & 8 & 57.25 & 12 & 47.00 & 9 & 42.17 & $\mathbf{2}$ \\
\hline Project Management Metrics & 26.89 & 15 & 59.75 & 11 & 22.87 & 16 & 10.33 & 16 \\
\hline Project Success Criteria & 32.28 & 14 & 54.00 & 14 & 32.13 & 15 & 18.00 & 13 \\
\hline Benchmarking & 26.89 & 16 & 60.75 & 10 & 17.63 & 17 & 16.67 & 14 \\
\hline Knowledge Management and PMIS & 39.50 & 12 & 47.50 & 16 & 46.75 & 10 & 24.50 & 9 \\
\hline \multicolumn{1}{|c|}{ Number of organizations assessed } & 18 & & 4 & & & 8 & & 6 \\
\hline
\end{tabular}

In order to test if the organization size has influence on the implementation of processes, the non-parametric Kruskal-Wallis test was used. A pairwise comparison 
was made. When the null hypothesis of Kruskal-Wallis was rejected $(p<0.05)[18]$ the LSD (Least Significant Difference) Fisher was used to identify the sample which had the stochastically dominate size (Table 5). Positive differences were identified with a $(+)$, meaning that a certain size has an average significantly higher than other size. Negative differences were identified with a (-), meaning the opposite. When no statistically significant differences were observed then the cells were left in blank.

Table 5. Summary of statistically significant differences, between organization sizes, for PM and Portfolio Management processes and OE areas.

\begin{tabular}{|c|c|c|c|c|}
\hline \multicolumn{2}{|c|}{ Project Management Processes } & Large & Medium & Small \\
\hline \multirow{3}{*}{ Create Work Breakdown Structure } & Large & & & + \\
\hline & Medium & & & + \\
\hline & Small & - & - & \\
\hline \multirow{3}{*}{ Develop Schedule } & Large & & & + \\
\hline & Medium & & & + \\
\hline & Small & - & - & \\
\hline \multirow{3}{*}{ Direct and Manage Project Execution } & Large & & + & + \\
\hline & Medium & - & & \\
\hline & Small & - & & \\
\hline \multirow{3}{*}{ Perform Integrated Change Control } & Large & & + & + \\
\hline & Medium & - & & \\
\hline & Small & - & & \\
\hline \multirow{3}{*}{ Control Schedule } & Large & & & + \\
\hline & Medium & & & + \\
\hline & Small & - & - & \\
\hline \multirow{3}{*}{ Control Costs } & Large & & & + \\
\hline & Medium & & & + \\
\hline & Small & - & - & \\
\hline \multirow{3}{*}{ Report Performance } & Large & & + & + \\
\hline & Medium & - & & + \\
\hline & Small & - & - & \\
\hline \multicolumn{2}{|c|}{ Portfolio Management Processes } & Large & Medium & Small \\
\hline \multirow{3}{*}{ Categorize Components } & Large & & + & + \\
\hline & Medium & - & & \\
\hline & Small & - & & \\
\hline \multirow{3}{*}{ Communicate Portfolio Adjustment } & Large & & + & + \\
\hline & Medium & - & & \\
\hline & Small & - & & \\
\hline \multicolumn{2}{|c|}{ Organizational Enablers Areas } & Large & Medium & Small \\
\hline \multirow{3}{*}{$\begin{array}{l}\text { Organizational Project Management Policy \& } \\
\text { Vision }\end{array}$} & Large & & & + \\
\hline & Medium & & & \\
\hline & Small & - & & \\
\hline \multirow{3}{*}{ Strategic Alignment } & Large & & & + \\
\hline & Medium & & & \\
\hline & Small & - & & \\
\hline \multirow{3}{*}{ Organizational Structures } & Large & & & + \\
\hline & Medium & & & + \\
\hline & Small & - & - & \\
\hline \multirow{3}{*}{ Competency Management } & Large & & & + \\
\hline & Medium & & & \\
\hline & Small & - & & \\
\hline \multirow{3}{*}{$\begin{array}{l}\text { Organizational Project Management } \\
\text { Methodology }\end{array}$} & Large & & & + \\
\hline & Medium & & & \\
\hline & Small & - & & \\
\hline
\end{tabular}

Results showed that Large organizations have positive differences compared to Small organizations in all PM processes. When compared to the Medium 
organizations, only three of the seven processes have positive differences. Medium organizations show positive differences compared to Small organizations in five of the seven processes. The results suggest that the maturity of the implementation of the processes signalled in Table 5 is dependent of the IST organizations' size.

Regarding the analysis of the Portfolio Management processes, and based on the results presented on Table 5, Large organizations show positive differences compared to Medium and Small organizations. Thus, it seems that as in PM processes, the Large organizations are the ones that present a greater maturity in the implementation of Portfolio Management processes.

In OE areas, Large organizations show positive differences in the five areas when compared to Small organizations. Medium organizations show positive differences only in the Organizational Structures when compared to Small organizations. Curiously, for OE areas, there are no statistically significant differences between Large and Medium organizations, unlike PM and Portfolio Management processes.

\section{Conclusions and Future Research}

The main objectives of this study were to examine the state of PM maturity of IST Portuguese organizations, and also to identify and compare the PM and Portfolio Management processes and $\mathrm{OE}$ areas, for different organization sizes.

An important limitation of this study was the sample size. Indeed, only eighteen organizations were analysed making hard the discussion of the results and not allowing the generalization to other IST organizations. However, results may be used as a guide, for the IST organizations. That is, according to their size, organizations can have an idea of which of the PM and Portfolio Management processes and OE areas are mostly implemented. This knowledge can help organizations to improve their PM maturity.

Large IST organizations stand out from Medium and Small organizations, since they globally presented the best results. Deepening in the results, there are positive differences for Small organizations in 7 PM processes (Create Work Breakdown Structure, Develop Schedule, Direct and Manage Project Execution, Perform Integrated Change Control, Control Schedule, Control Costs and Report Performance), 2 Portfolio Management processes (Categorize Components and Communicate Portfolio Adjustment) and $5 \mathrm{OE}$ areas (Organizational Project Management Policy \& Vision, Strategic Alignment, Organizational Structures, Competency Management and Organizational Project Management Methodology). Regarding the Medium organizations, the differences observed are related to 3 PM processes (Direct and Manage Project Execution, Perform Integrated Change Control and Report Performance) and 2 Portfolio Management processes (Categorize Components and Communicate Portfolio Adjustment). Therefore, the referred processes are those that effectively differentiate the Large IST organizations, from Medium and Small sizes. Despite these processes and areas are not the most implemented in the eighteen organizations, they allow Large organizations to be more mature than the others. 
Being a pioneer study in this area in the world, it is not possible to compare the results and conclude whether these Portuguese organizations present a good or bad PM maturity. Taking into account the results, we can only conclude that there is a significant opportunity to improve the implementation of PM practices in IST Portuguese organizations. For future work, it would be interesting, in parallel with a more representative study of the population, i.e., using a larger sample, to create a model that would simplify the selection of priority PM practices to be implemented by the different types of organization, serving as a benchmarking tool.

\section{References}

1. Demir, C., Kocabas, I.: Project Management Maturity Model (PMMM) in educational organizations. World Conference on Learning, Teaching and Administration Papers. 9, (2010)

2. Shi, Q.: Rethinking the implementation of project management: A Value Adding Path Map approach. International Journal of Project Management. 29(3), 295--302 (2011)

3. Andersen, E.S., Jessen, S.A.: Project maturity in organisations. International Journal of Project Management. 21(6), 457--461 (2003)

4. Jugdev, K., Thomas, J.: Project management maturity models: The silver bullets of competitive advantage. Project Management Journal, (2002)

5. Pazderka, M., Grechenig, T.: Project Management Maturity Models: Towards Best Practices for Virtual Teams. In: 2007 IEEE International Engineering Management Conference. pp. 83--88. Lost Pines, TX. (2007)

6. Schlichter, J., Tamimi, A., Cooke-Davies, T.J.: Linking Project Management Practice to Organizational Strategy in a Saudi Arabian Government Department. In: PMI Global Congress Proceedings. Orlando, Florida. (2009)

7. Cooke-Davies, T.J., Schlichter, J., Bredillet, C.: Beyond the PMBOK guide. In: Proceedings of the 32nd Annual Project Management Institute 2001 Seminars and Symposium. Nashville, TN. (2001)

8. Berssaneti, F.T., Carvalho, M.M.d., Muscat, A.R.N.: Impacto dos modelos de referência e maturidade no gerenciamento de projetos: estudo exploratório em projetos de tecnologia da informação. Production, 22(3). pp. 404--435. (2012)

9. PMI: Organizational Project Management Maturity Model (OPM3) - Third Edition. Knowledge Foundation. Project Management Institute, Inc. Pennsylvania - USA. (2013)

10.Lima, R.R., Anselmo, J.L.: Gerenciamento de Projetos com OPM3 ${ }^{\text {TM}}$ : O caso Promon. In: PMI Global Congress Proceedings. Buenos Aires, Argentina. (2004)

11.Jia, G., Cao, L., Chen, J., Zhou, S., Wang, J.: Application of Organizational Project Management Maturity Model (OPM3) to Construction in China: An Empirical Study. In: Proceedings of the International Conference on Information Management, Innovation Management and Industrial Engineering. Taiwan. (2008)

12.Zaguir, N.A., Martins, M.R.: Revisão Critica do OPM3: um estudo de redundâncias. Revista Gestão Industrial. 3(1). (2007)

13.Pinto, J.A.: 100 Organizational Improvements using OPM3 ${ }^{\circledR}$. In: 2013 PMI Global Congress Proceedings. New Orleans, Louisiana - USA. (2013)

14.Pinto, J.A., Williams, N.: Country Project Management Maturity. In: 2013 PMI Global Congress Proceedings. Istanbul - Turkey. (2013)

15.Silva, D., Tereso, A., Fernandes, G., Pinto, J.A.: OPM3 ${ }^{\circledR}$ Portugal Project: Analysis of Preliminary Results. Procedia Technology, 16, 1027--1036. (2014)

16.EC: Annual Report on European SMEs 2012/2013. (2013)

17.IBM: IBM SPSS Statistics for Windows. IBM Corp. Armonk, NY. (2013) 
18.Field, A.: Discovering statistics using SPSS. SAGE. Los Angeles. (2009) 